\title{
Influence of Welding Parameters On Grain Size, Haz and Degree of Dilution in 6063-t5 Alloy. Optimisation Through the Taguchi Method of the Gmaw Welding Process.
}

Jose Luis Meseguer Valdenebro ( $\sim$ jlmeseguer507@gmail.com )

UPM

Eusebio José Martínez Conesa

Universidad Politécnica de Cartagena

Antonio Portoles

University of Madrid

\section{Research Article}

Keywords: Weld, Aluminum, HAZ, Taguchi, Optimisation

Posted Date: January 14th, 2022

DOI: https://doi.org/10.21203/rs.3.rs-1232786/v1

License: (c) (i) This work is licensed under a Creative Commons Attribution 4.0 International License.

Read Full License 


\section{Abstract}

The aim of this work is to carry out the design of experiments that determine the influence of the welding parameters using Taguchi's method on the grain size, HAZ, and the degree of dilution in 6063-T5 alloy. The welding process used is GMAW and the welding parameters are power, welding speed and bevel spacing. The study of the influence of the welding parameters on the measurements made in the welding (which are the size of heat affected zone, the degree of dilution, and the grain size) allows one to determine the quality of the joint . In addition, the welding parameter most influential in minimising the three measurements will be determined.

\section{Introduction}

Aluminium alloys are characterised by having more or less soft mechanical properties depending on the quality and quantity of the alloying elements that are present in the aluminium matrix. [1]. These alloying elements can be lost due to the thermal input received when it comes to a weld. On the other hand, the size of the grain in the alloy also determines the mechanical properties of the aluminium alloy, being more resistant as the size of the grain decreases; and finally there is the size of the HAZ that is also relevant as the smaller is its size, the better the properties of the weld joint. The grain size [2] is determined by microscopic analysis using comparative charts according to the ASTM E112 [3] and NF ISO 643 [4] standards. There are computer programmes that by using a microstructure of a weld can estimate the size of the grains by means of polarisation micrographs and image orientation [5]. There are other programmes that determine the size of the grain from statistical analysis by analysing the size of the grain from the parameters of the grain [6].

The dilution between the filler material and the base material is defined as the ratio in which the base metal mixes with the molten metal [7]. The dilution is expressed by the following expression:

Dilution $(\%)=\frac{\text { molten base metal }}{\text { Total Molten metal }}$ (eq. 1)

The dilution is proportional to the thermal input of the heat source [8], [9], that is, the greater the thermal input, the greater the dilution [10]. In the present work, both the thermal input and the dilution obtained from the size of the weld bead, and the relationship between the molten base material and the total molten material are analysed. The lower the dilution, the lower the presence of base material in the weld bead and the better the quality of the weld bead.

The classic design of experiments aims to identify the factors that affect the mean response and their influence on a target value. The Taguchi design of experiments has the advantage over the classical design of experiments in reducing the variability in the deviation from the mean target value. [11]-[16].

The robust parameter design used by the Taguchi designs (orthogonal matrices) analyses the influence of the factors by means of a few experiments. Taguchi's experiment designs are balanced; that is, no 
factor is analysed independently of each other. Accordingly, it is sufficient to perform nine experiments to evaluate the size of the weld grain, the size of the HAZ, and the dilution of the filler material.

There are different studies that have performed optimisation of welding processes using Taguchi's design of experiments. These studies optimised the weld bead based on the electrical parameters used from the source. [17]-[19]. There is also an optimisation study that evaluated the welding thermal cycle [20]. All these studies were carried out using the GMAW welding process. [21]-[24].

The present work aims to study the effect of welding parameters, that is, power (P), welding speed (Vs) and edge separation (Sp) on grain size, HAZ size, and dilution in the weld bead.

\section{Experimental Procedure}

In a previous work [17], the same weld was evaluated by determining the influence that the aforementioned parameters have on the geometry of the weld bead. In reference [17], conducted by the author of this paper, the following is indicated:

The experimental procedure is carried out with a robot welding arm (brand ABB, model IR 1400), as shown in Figure 1a. The robotic arm has six degrees of freedom of movement and a system controls the welding parameters. The welding robot presents high precision, which guarantees the correct finish of the joint. The elements to be joined are nine tubes with an outside diameter of $50 \mathrm{~mm}$, a thickness of $2 \mathrm{~mm}$, and a length of $150 \mathrm{~mm}$, which have been cut longitudinally and subsequently joined by a welding bead. To be able to make the longitudinal connection of the tube, a carbon steel tool was designed to support the two parts of the aluminium tube before they were welded. The tooling is shown in Figure 1b.

Aluminium 6063-T5 is usually supplied in the form of a tube and not in the form of sheets [36]. The filler metal used is ER-5356, which is most suitable for welding 6063-T5 [25]. The diameter of the wire used is $1 \mathrm{~mm}$, and the protective gas is $99 \%$ argon. The type of transfer used by the welding process is short arc transfer [2], [24], [26]. The chemical compositions of the base metal and the filler metal are given in Tables 1 and 2, respectively.

Table 1

Base metal chemical composition

\begin{tabular}{|llllllll|}
\hline $\mathrm{Si}$ & $\mathrm{Fe}$ & $\mathrm{Cu}$ & $\mathrm{Mn}$ & $\mathrm{Mg}$ & $\mathrm{Cr}$ & $\mathrm{Zn}$ & $\mathrm{Ti}$ \\
\hline $0.20-0.60$ & 0.35 & 0.10 & $0.45-0.90$ & $0.45-0.90$ & 0.10 & 0.10 & 0.10 \\
\hline
\end{tabular}

Table 2

Chemical composition of filler metal

\begin{tabular}{|llllllll|}
\hline $\mathrm{Mn}$ & $\mathrm{Si}$ & $\mathrm{Ti}$ & $\mathrm{Cu}$ & $\mathrm{Mg}$ & $\mathrm{Zn}$ & $\mathrm{Be}$ & $\mathrm{Fe}$ \\
\hline 0.05 & 0.25 & 0.06 & 0.10 & 4.5 & 0.10 & 0.0008 & 0.4 \\
\hline
\end{tabular}

\subsection{Design of experiments}


Three variables with three levels each were used to develop nine welding experiments according to the Taguchi design with an L9 orthogonal array. Table 3 shows the three variables used: Power $(P)$, welding speed (Vs) and edge separation (Sp).

Table 3

Factor levels

\begin{tabular}{|llll|}
\hline Level & $\mathbf{P}(\mathbf{W})$ & $\mathbf{V s}(\mathrm{mm} / \mathbf{s})$ & $\mathbf{S p}(\mathrm{mm})$ \\
\hline 1 & 1557 & 11.5 & 0.0 \\
\hline 2 & 1673 & 12.25 & 1.0 \\
\hline 3 & 1744 & 13 & 1.2 \\
\hline
\end{tabular}

The three factorial levels arranged in ascending order were selected. For the power, $1557 \mathrm{~W}$ represents the minimum value of the power used in the experiment, $1673 \mathrm{~W}$ represents the intermediate value of power, and $1744 \mathrm{~W}$ represents the maximum value of the power used in the experiment. In the same way, it is preceded by the welding speed and the separation of the plate edges, where the value of the first level corresponds to the minimum value of the variable, the value of the second level corresponds to an intermediate value of the variable, and the value of the third level corresponds to the highest value of the variable [17].

To determine the matrix of the nine experiments using Taguchi's method, the statistical software Minitab [27] is used. Table 4 shows the nine experiments proposed using the Taguchi methodology. The power is obtained from the product of multiplying the intensity by the voltage. Table 5 shows the intensity and volt age values used for the three power values used in the experimental design.

Table 4

Matrix of experiments

\begin{tabular}{|llll|}
\hline Experiment $\mathbf{N}^{\mathbf{0}}$ & $\mathbf{P}(\mathbf{W})$ & $\mathbf{V s}(\mathrm{mm} / \mathbf{s})$ & $\mathbf{S p}(\mathrm{mm})$ \\
\hline 1 & 1557 & 11.5 & 0.0 \\
\hline 2 & 1557 & 12.25 & 1.0 \\
\hline 3 & 1557 & 13.0 & 1.2 \\
\hline 4 & 1673 & 11.5 & 1.0 \\
\hline 6 & 1673 & 12.25 & 1.2 \\
\hline 7 & 1673 & 13.0 & 0.0 \\
\hline 8 & 1744 & 11.5 & 1.2 \\
\hline 9 & 1744 & 12.25 & 0.0 \\
\hline
\end{tabular}

Table 5 shows the electrical parameters used for each case of power used. 
Table 5

Values of intensity and voltage used in each

power value

\begin{tabular}{|lll|}
\hline Power (W) & Intensity (A) & Voltage (V) \\
\hline 1557 & 90 & 17.3 \\
1673 & 94 & 17.8 \\
1744 & 98 & 17.8 \\
\hline
\end{tabular}

\section{Discussion Of Results}

Figure 2 shows the 9 welds corresponding to each of the experiments carried out according to what is indicated in Table 4. These welds have been polished with different grain sizes as indicated in the reference [17].

\subsection{Macrographs of the nine experiments performed}

To measure the grain size, the Grani software is used. It allows the "G" index to be calculated with precision according to the standards ASTM E112 [3] and NF ISO 643 [4]. A complete set of measurements is performed for the 9 experiments using the Grani software.

On the macrograph, the grain size is measured in the thermally affected area, that is, in the HAZ. For each experiment, the G-index of the grain and the number of grains is measured. The Grani software uses the Hilliard method $[23,24]$ to determine these values. Figure 3 shows the measurements made in each experiment. A red circle marks the area where the grain's G-index and the number of grains have been measured. 
Table 6

Grain size values obtained in the HAZ

\begin{tabular}{|lll|}
\hline Experiment $\mathbf{N}^{\circ}$ & Grain G index & Number of grains \\
\hline 1 & 4 & 16 \\
\hline 2 & 4 & 16 \\
\hline 3 & 3.2 & 12 \\
\hline 4 & 5.1 & 23 \\
\hline 5 & 5.2 & 24 \\
\hline 7 & 4 & 16 \\
\hline 8 & 2 & 8 \\
\hline 9 & 3.6 & 14 \\
\hline
\end{tabular}

Figure 4 represents the relationship between the G index of the ASTM standard and the number of grains identified by the Grani programme. Therefore, the grain size is evaluated and not the letter number since the relationship is the same.

To evaluate the effect of each of the variables on the number of grains, the following multivariate linear regression equation is obtained:

Numberofgrain $=20.3-0.0011 \cdot P, W-0.22 \cdot V s, \mathrm{~mm} / \mathrm{s}+0.81 \cdot \mathrm{Sp}, \mathrm{mm}$ (eq. 2$)$

Table 7

Analysis of Variance. ANOVA

\begin{tabular}{|llllll|}
\hline Source & DF & Adj SS & Adj MS & F-Value & P-Value \\
\hline Regression & 3 & 1.845 & 0.6149 & 0.02 & 0.997 \\
\hline P, W & 1 & 0.065 & 0.0651 & 0.00 & 0.969 \\
\hline Vs, mm/s & 1 & 0.167 & 0.1667 & 0.00 & 0.951 \\
\hline Sp, mm & 1 & 1.613 & 1.6129 & 0.04 & 0.848 \\
\hline Error & 5 & 198.155 & 39.6311 & & \\
\hline Total & 8 & 200.000 & & & \\
\hline
\end{tabular}

In the analysis of variance in Table 7 the influence of each of the variables on grain size is determined.

The three P-values shown are large, that is, they have no significant influence on the number of grains of the aluminium weld. Therefore, these three variables do not affect the number of grains in the weld. 
In accordance with the above, the effect of the three main variables on the number of grains is not further analysed because they have not influenced the number of grains.

\subsection{Size of the HAZ in each experiment performed}

The size of the HAZ of each weld is measured using a profile meter. Figure 5 shows the test tubes carried out in each experiment on which the size of the HAZ is measured using the profile meter.

Figure 6 shows the micrograph of the HAZ made at each of the joints.

In each of the experiments carried out, the size of the HAZ is measured, being reflected in red on each of the experiments. The HAZ values obtained are as follows:

Table 8

HAZ size for each experiment

\begin{tabular}{|ll|}
\hline Experiment $\mathbf{N}^{\circ}$ & Size of HAZ (mm) \\
\hline 1 & 0.64 \\
\hline 2 & 0.65 \\
\hline 3 & 0.76 \\
\hline 4 & 0.89 \\
\hline 5 & 1.17 \\
\hline 6 & 0.84 \\
\hline 7 & 1.27 \\
\hline 9 & 0.92 \\
\hline
\end{tabular}

To evaluate the effect of each of the variables on the size of the HAZ, the multivariate linear regression equation is obtained:

SizeofHAZ $=-1.30+0.001831 \cdot P, W-0.0778 \cdot V s, \mathrm{~mm} / \mathrm{s}+0.1495 \cdot \mathrm{Sp}, \mathrm{mm}$ (eq. 3)

The adjustment of equation 3 has an R2 (adjusted) $=51.87 \%$, which is a long way from $95 \%$.

Figure 7. Representation of each of the variables with respect to the size of the HAZ 
Table 9

Analysis of Variance. ANOVA

\begin{tabular}{|llllll|}
\hline Source & DF & Adj SS & Adj MS & F-Value & P-Value \\
\hline Regression & 3 & 0.25504 & 0.08501 & 3.87 & 0.089 \\
\hline P, W & 1 & 0.17923 & 0.17923 & 8.17 & 0.035 \\
\hline Vs, mm/s & 1 & 0.02042 & 0.02042 & 0.93 & 0.379 \\
\hline Sp, mm & 1 & 0.05540 & 0.05540 & 2.52 & 0.173 \\
\hline Error & 5 & 0.10971 & 0.02194 & & \\
\hline Total & 8 & 0.36476 & & & \\
\hline
\end{tabular}

In the analysis of variance Table 9 the influence of each of the variables on grain size is determined. The three P-values shown are small, that is, they have a significant influence on the size of the HAZ of the aluminium weld. Therefore, these three variables significantly affect the HAZ size of the weld.

The variable that has the most influence is power, $\mathrm{P}$; it is followed by the edge separation, $\mathrm{Sp}$, and finally the welding speed, Vs. The following graph shows the effect of each of the variables on the size of the HAZ.

From Figure 8 the specific weight of each of the variables is obtained: P (53\%); Sp (29\%); Vs (18\%) on the size of the HAZ.

\subsection{Dilution obtained in each of the experiments performed}

Figure 9 shows area of dilution in the weld bead (area marked in red). From equation 1 the dilution ratio is determined by dividing the total molten base by the total base metal.

Figure 9 shows the dilution values (\%), weld bead area, and molten base metal area. The area of the weld bead was determined in reference [17] by measuring it with a profile meter. 
Table 10

For each experiment, dilution values, total molten metal sizes, and molten base metal sizes

\begin{tabular}{|llll|}
\hline Experiment No & Weld bead area & Molten base metal area & Dilution (\%) \\
\hline 1 & $1.86 \mathrm{E}-05$ & $9.72 \mathrm{E}-06$ & $52 \%$ \\
\hline 2 & $1.25 \mathrm{E}-05$ & $4.65 \mathrm{E}-06$ & $21 \%$ \\
\hline 3 & $1.16 \mathrm{E}-05$ & $3.82 \mathrm{E}-06$ & $12 \%$ \\
\hline 4 & $1.91 \mathrm{E}-05$ & $9.16 \mathrm{E}-06$ & $37 \%$ \\
\hline 5 & $1.92 \mathrm{E}-05$ & $1.00 \mathrm{E}-05$ & $46 \%$ \\
\hline 7 & $1.57 \mathrm{E}-05$ & $7.31 \mathrm{E}-06$ & $47 \%$ \\
\hline 8 & $2.29 \mathrm{E}-05$ & $1.22 \mathrm{E}-05$ & $43 \%$ \\
\hline 9 & $1.99 \mathrm{E}-05$ & $1.06 \mathrm{E}-05$ & $53 \%$ \\
\hline
\end{tabular}

\subsubsection{Determination of the molten base metal area. Degree of dilution}

The area of the molten base metal is determined from the CAD representation of the weld joint using the profile gauge and the initial geometry of the tubular profile before it is welded. The bead is superimposed on the tube geometry and the molten base metal found in the weld metal is obtained. Figure 10 represents the weld bead and base metal. Edge separation, $\mathrm{Sp}$, is considered in determining the degree of dilution.

To evaluate the effect of each of the variables on the dilution of the base metal with the weld metal, the multivariate linear regression equation is obtained:

Dilution $=0.207+0.000834 \cdot P, W-0.0889 \cdot V s, \frac{m m}{s}-0.1616 \cdot S p, m m($ eq. 4$)$

The fit of equation 4 has an R2 (adjusted) $=70.09 \%$, which is acceptable.

Figure 11 represents the trend of each of the welding variables against dilution in the weld bead. As the power increases, the dilution in the weld bead increases, and as both Vs and Sp decrease, the dilution in the weld bead decreases.

In the analysis of variance in Table 11 the influence of each of the variables on the degree of dilution is determined. The three P-values shown are small, that is, they have a significant influence on the degree of dilution in the weld bead. Therefore, these three variables significantly affect the degree of dilution in the weld bead. 
Table 11

Analysis of Variance. ANOVA

\begin{tabular}{|llllll|}
\hline Source & DF & Seq SS & Seq MS & F-Value & P-Value \\
\hline Regression & 3 & 0.12859 & 0.042862 & 7.25 & 0.029 \\
\hline P, W & 1 & 0.03719 & 0.037188 & 6.29 & 0.054 \\
\hline Vs, mm/s & 1 & 0.02667 & 0.026667 & 4.51 & 0.087 \\
\hline Sp, mm & 1 & 0.06473 & 0.064731 & 10.95 & 0.021 \\
\hline Error & 5 & 0.02957 & 0.005914 & & \\
\hline Total & 8 & 0.15816 & & & \\
\hline
\end{tabular}

In Figure 12, the influence of each of the variables on the degree of dilution is presented. The variable that has the most influence is the edge separation, Sp, followed by the power, P; and finally, the welding speed, Vs.

From Figure 12, the specific weight of each of the variables (P (32\%); Sp (42\%); Vs (27\%)) on the dilution of the base metal in the weld bead is obtained.

\section{Optimisation Of Results}

Once the experiments have been carried out and the grain size, the size of the HAZ and the dilution in the weld have been measured, the analysis of Variance is used to determine the influence of the welding parameters, $\mathrm{P}, \mathrm{Vs}$, and Sp optimisation using the Taguchi method with the statistical programme Minitab [22]. The criterion to be used in the Taguchi optimisation is "the smallest is the best" for both the degree of dilution and the size of the HAZ.

The grain size will not be analysed because, as indicated above, there is no relationship between the welding variables: $\mathrm{P}, \mathrm{Vs}$ and $\mathrm{Sp}$ and therefore its evaluation is discarded..

\subsection{Optimisation of Taguchi}

The noise signal $(\mathrm{S} / \mathrm{N})$ for the case "smallest is best" is determined as follows:

- Noise signal $(\mathrm{S} / \mathrm{N})$ : the smaller the better

The $\mathrm{S} / \mathrm{N}$ ratio is defined as:

$S / N_{i}=-10 \log \left(\frac{1}{n} \cdot \sum_{j=1}^{n} Y_{i j}^{2}\right)$ (eq. 5)

Table 12 shows the $\mathrm{S} / \mathrm{N}$ responses of the welding parameters for the size of the HAZ and for the percentage of dilution. 
Table 12

$\mathrm{S} / \mathrm{N}$ response for individually analysed welding

parameters

\begin{tabular}{|llll|}
\hline Level & $\mathbf{P}(\mathbf{W})$ & Vs $(\mathrm{mm} / \mathrm{s})$ & Sp $(\mathrm{mm})$ \\
\hline Size of HAZ & & & \\
\hline 1 & 3.33395 & 0.93751 & 2.03835 \\
\hline 2 & 0.38763 & 1.03409 & 2.05518 \\
\hline 3 & 0.01993 & 1.76992 & -0.35202 \\
\hline Delta & 3.314 & 0.832 & 2.407 \\
\hline Rank & 1 & 3 & 2 \\
\hline$\%$ influence & $51 \%$ & $13 \%$ & $37 \%$ \\
\hline$\%$ Dilution & & & \\
\hline 1 & 12.551 & 7.216 & 5.917 \\
\hline 2 & 7.313 & 8.605 & 10.607 \\
\hline 3 & 7.492 & 11.535 & 10.831 \\
\hline Delta & 5.238 & 4.319 & 4.913 \\
\hline Rank & 1 & 3 & 2 \\
\hline \% influence & $36 \%$ & $30 \%$ & $34 \%$ \\
\hline
\end{tabular}

Table 13 shows the comparison of the influence presented by the welding variables obtained from the variance and the influence obtained for these variables from the Taguchi optimisation, with the criterion: "the smallest is the best". 
Table 13

Comparison of the influence of the ANOVA variables vs Taguchi optimisation

\begin{tabular}{|lll|}
\hline Parameter & ANOVA & Taguchi's Optimisation \\
\hline Size of HAZ & & \\
\hline P, W & $53 \%$ & $51 \%$ \\
\hline Vs, mm/s & $29 \%$ & $13 \%$ \\
\hline Sp, mm & $18 \%$ & $37 \%$ \\
\hline Dilution & & \\
\hline P, W & $32 \%$ & $36 \%$ \\
\hline Vs, mm/s & $27 \%$ & $30 \%$ \\
\hline Sp, mm & $42 \%$ & $34 \%$ \\
\hline
\end{tabular}

In the table above, it is verified that the power has the most significant influence, of the same order of magnitude for the ANOVA analysis and for the Taguchi method, both for the size of the HAZ and for the dilution. However, the same is not the case for $\mathrm{Vs}$ and $\mathrm{Sp}$, where the influences of the variables for both dilution and HAZ size are inversely proportional. From this it follows that the study of variance would not be a valid reference for the desired optimisation, it only indicates what is the mean influence of each of the variables on each of the measurements made.

The optimal parameters to obtain the minimum HAZ are the following:

The optimal parameters to obtain the minimum dilution are the following:

\subsection{Optimised combination of process parameters}

Once the influence of each of the variables on HAZ size and dilution has been separately analysed, Figure 15 shows the optimal combination of the three welding variables, $\mathrm{P}, \mathrm{Vs}$ and $\mathrm{Sp}$, to obtain minimal dilution and minimal HAZ.

The optimisation graph shows the effect of each input variable, represented in columns, on the weld measurements carried out; that is, the responses that are presented in rows. The vertical red lines in the graph represent the configuration of the current value. The numbers shown at the top of a column show the configuration of the current input variables, presented in red. The horizontal blue lines and numbers represent the answers for the current factor level.

Desirability in general terms evaluates the effectiveness with which a combination of input variables satisfies the goals that have been defined for the answers. The individual desirability (d) evaluates how the configuration optimises an individual response; the composite desirability (D) evaluates how the configuration optimises a set of responses in general. Desirability has a range of $0-1: 1$ represents the 
ideal situation and 0 indicates that one or more answers are outside acceptable limits. It can be seen that the composite desirability has a value of 0.8971 ; that is, overall the responses have an intermediate desirability.

The minimum value of the dilution obtained in the figure above is $y=15 \%$, corresponding to the value: 0.1559 , having a real minimum value in the experiments carried out of $12 \%$ dilution (see Table 10 ). Similarly, for the HAZ, the minimum value obtained in the figure above is $y=0.71 \mathrm{~mm}$ and the minimum value obtained in the experiments is $0.64 \mathrm{~mm}$ (see Table 8); the welding parameters to obtain the minimum values in both cases are: $\mathrm{P}=1557 \mathrm{~W} ; \mathrm{Vs}=13 \mathrm{~mm} / \mathrm{s} ; \mathrm{Sp}=1.2 \mathrm{~mm}$

\section{Conclusions}

- According to the analysis of variance carried out in Table 7, it is determined that there is no relationship between the welding parameters and the size of the grain obtained in the experiments carried out.

- In accordance with the previous conclusion, the optimisation of the variables was not continued to obtain the smallest possible grain size since there is no relationship between these and the grain size.

- Regarding the size of the HAZ, the P has an influence of $53 \%$, the Vs has an influence of $18 \%$ and the Sp has an influence of $29 \%$.

- Regarding the degree of dilution, $\mathrm{P}$ has an influence of $32 \%$, Vs has an influence of $27 \%$ and Sp has an influence of $42 \%$.

- A Taguchi optimisation is performed for the lowest possible value in both the size of the HAZ and in the dilution.

- To obtain the minimum size of HAZ the optimal welding parameters are, $\mathrm{P}=1557 \mathrm{~W}$; Vs $=13 \mathrm{~mm} / \mathrm{s}$; $S p=0 \mathrm{~mm}$. From these values a minimum value in the HAZ of $0.53 \mathrm{~mm}$ is obtained.

- To obtain the minimum dilution value, the optimal welding parameters are, $\mathrm{P}=1557 \mathrm{~W}, \mathrm{Vs}=13 \mathrm{~mm}$ $\mathrm{s}$ and $\mathrm{Sp}=1 \mathrm{~mm}$. From these values a minimum dilution value of $18 \%$ is obtained.

- An optimisation of the welding parameters is carried out to obtain a minimum value in both the HAZ and in the degree of dilution, producing the following values: $P=1557 \mathrm{~W} ; \mathrm{Vs}=013 \mathrm{~mm} / \mathrm{s} ; \mathrm{Sp}=1.2$ $\mathrm{mm}$.

\section{Abbreviations}

GMAW Gas Metal Arc Welding

HAZ Heat Affected Zone 


\section{Declarations}

a. Funding (information that explains whether and by whom the research was supported).

Answer: The authors declare that no funds, grants, or other support were received during the preparation of this manuscrip

b. Conflicts of interest/Competing interests (include appropriate disclosures)

Answer: The authors have no relevant financial or non-financial interests to disclose."

c. Availability of data and material (data transparency)

Answer: The photos and images have been obtained from the tests carried out in the laboratories of the co-author: Antonio Portoles. The Minitab statistical program is licensed by co-author: Eusebio Jose Martinez Conesa.

d. Code availability (software application or custom code)

Answer: The Minitab statistical program is licensed by co-author: Eusebio Jose Martinez Conesa.

e. Ethics approval (include appropriate approvals or waivers)

Answer: No apply

f. Consent to participate (include appropriate statements)

Answer: No apply

g. Consent for publication (include appropriate statements)

Answer: No apply

h. Authors' contributions (optional: please review the submission guidelines from the journal whether statements are mandatory)

Answer: No apply

\section{References}

1. López EAT, Ramirez AJ (2015) «Inhibición de la formación de compuestos intermetálicos en juntas aluminio-acero soldadas por fricción-agitación», Revista de Metalurgia, vol. 51, n. 4, p. 053,

2. de las Cuevas F, Aguilar C, Sevillano JG (2018) «Un estudio adicional de la cinética de recristalización y crecimiento de grano del acero twip laminado en frío», Revista de Metalurgia, vol. 54, n. $^{\circ} 4$, p. 131 , 
3. «ASTM E112 - 13.Standard Test Methods for Determining Average Grain Size»

4. «ISO 643:2019. Aciers - Détermination micrographique de la grosseur de grain apparente\&\#187

5. Heilbronner R (2000) «Automatic grain boundary detection and grain size analysis using polarization micrographs or orientation images», Journal of Structural Geology, vol. 22, n. ${ }^{\circ}$ 7, pp. 969-981,

6. Seward-Thompson B, Hails yJ (1973) «An appraisal of the computation of statistical parameters in grain size analysis», Sedimentology, vol. 20, n. ${ }^{\circ}$ 1, pp. 161-169,

7. Delgado JA, Ambriz RR, Cuenca-Álvarez R, Alatorre N, Curiel FF (2016) «Efecto del calor de aporte sobre la transformación microestructural y las propiedades mecánicas en soldadura GTAW de un acero inoxidable ferrítico 409L», Revista de Metalurgia, vol. 52, n. ${ }^{\circ}$ 2, p. 068,

8. Meseguer-Valdenebro JL, Portolés A (2017) y E. Martínez-Conesa, «Ciclo térmico y soldabilidad de las aleaciones de aluminio», Revista de Metalurgia, vol. 53, n. ${ }^{\circ}$ 3, p. 103 ,

9. Meseguer-Valdenebro JL, Martinez-Conesa EJ, Serna J, Portoles yA (2016) «Influence of the welding parameters on the heat affected zone for aluminium welding», Thermal Science, vol. 20, n. ${ }^{\circ} 2$, pp. 643-653,

10. Hunt A, Kluken A, Edwards yG (1994) «Heat input and dilution effects in microalloyed steel weld metals», WELDING JOURNAL-NEW YORK- vol. 73, pp. 9-s,

11. Roy RK (2010) A primer on the Taguchi method. Society of Manufacturing Engineers

12. Cruz-Gonzalez CE, Gala-Barron HI, Mosquera-Artamonov JD (2016) y H. Gamez-Cuatzin, «Effect of pulsed current in the welding process of $6 \mathrm{AL} 4 \mathrm{~V}$ in titanium with and without filler metal», REVISTA DE METALURGIA, vol. 52, n. ${ }^{\circ}$,

13. Piccini JM, Svoboda HG (2017) «Effect of tool rotational speed and penetration depth on dissimilar aluminum alloys friction stir spot welds.», REVISTA DE METALURGIA, vol. 53, n. ${ }^{\circ} 1$,

14. Naik S, Das SR, Khatua yAK (2021) «Analysis on surface integrity and sustainability assessment in electrical discharge machining of engineered $\mathrm{Al}-22 \% \mathrm{SiC}$ metal matrix composite», Revista de Metalurgia, vol. 57, n. ${ }^{\circ} 4$, p. e210,

15. Grillo FF et al (2020) «Elaboration of synthetic slags containing marble waste and aluminum oxide used in steel desulfurization process». Revista de Metalurgia 56:174

16. Chinnadurai y T, Vendan SA (2016) «Prediction of material removal rate and surface roughness for wire electrical discharge machining of nickel using response surface methodology», Revista de Metalurgia, vol. 52, n. ${ }^{\circ}$ 4, pp. 10-3989,

17. Meseguer-Valdenebro JL, Portoles A (2018) y E. Matínez-Conesa, «Electrical parameters optimisation on welding geometry in the 6063-T alloy using the Taguchi methods», The International Journal of Advanced Manufacturing Technology, vol. 98, n. ${ }^{\circ}$ 9, pp. 2449-2460,

18. Martinez-Conesa EJ, Egea JA, Miguel V, Toledo C (2017) y J. L. Meseguer-Valdenebro, «Optimization of geometric parameters in a welded joint through response surface methodology», Construction and Building materials, vol. 154, pp. 105-114, 
19. Meseguer-Valdenebro JL, Serna J, Portoles A, Estrems M, Miguel V, Martínez-Conesa E (2016) «Experimental validation of a numerical method that predicts the size of the Heat Affected Zone. Optimization of the welding parameters by the Taguchi's method», Transactions of the Indian Institute of Metals, vol. 69, n. ${ }^{\circ}$ 3, pp. 783-791,

20. Meseguer-Valdenebro JL, Portoles A, Oñoro J (2017) «Numerical study of TTP curves upon welding of 6063-T5 aluminium alloy and optimization of welding process parameters by Taguchi' s method»,

21. Meseguer-Valdenebro JL, Martínez-Conesa EJ, Portolés yA (2019) «Numerical-experimental validation of the welding thermal cycle carried out with the MIG welding process on a 6063-T5 aluminium tubular profile», Thermal Science, n. $^{\circ} 00$, pp. 30-30,

22. Miguel V, Marín-Ortiz F, Manjabacas MC, Martínez-Conesa EJ, Martínez-Martínez A, Coello J (2015) «Optimización multiobjetivo del proceso de soldeo GMAW de la aleación AA 6063-T5 basado en la penetración y en la zona afectada térmicamente», Revista de Metalurgia, vol. 51, n. ${ }^{0}$ 1, p. 037,

23. Miguel V, Martínez-Conesa E, Segura F, Manjabacas M, Abellán yE (2012) «Optimización del proceso de soldadura GMAW de uniones a tope de la aleación AA 6063-T5 basada en la metodología de superficie de respuesta y en la geometría del cordón de soldadura», Rev. Metal, vol. 48, n. ${ }^{\circ}$ 5, pp. 333350 ,

24. Bloem C, Salvador M, Amigó V, Vicente yA (2007) «Comportamiento a fatiga de uniones soldadas GMAW de la aleación de aluminio AA 7020», Revista de metalurgia, vol. 43, n. 2, pp. 111-116,

25. «ASM I (1998) Metal Handbook. ASM International, USA»

26. Bloem CA, Salvador MD, Amigó V, Vicente A (2000) «Estudio microestructural y de resistencia de uniones soldadas de la aleación AW7020 por procedimiento MIG en función de la preparación de bordes», Revista de Metalurgia, vol. 36, n. ${ }^{\circ}$ 1, pp. 33-39,

27. Mathews PG (2005) Design of Experiments with MINITAB. ASQ Quality Press Milwaukee, WI, USA:

\section{Figures}


a

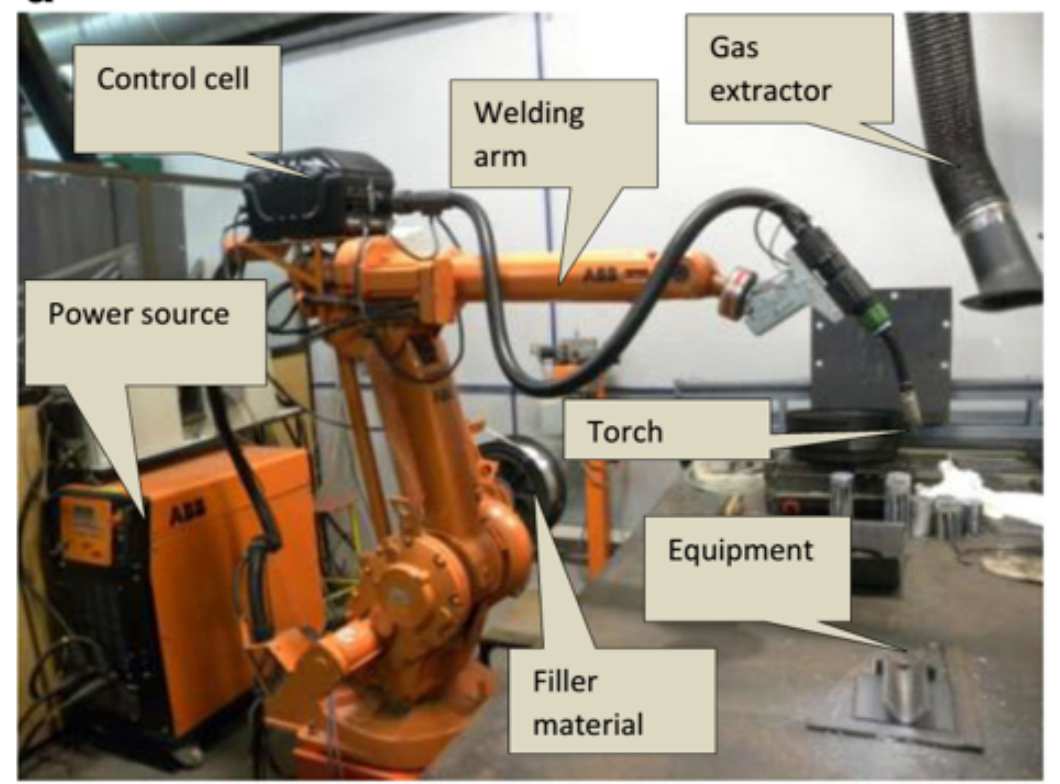

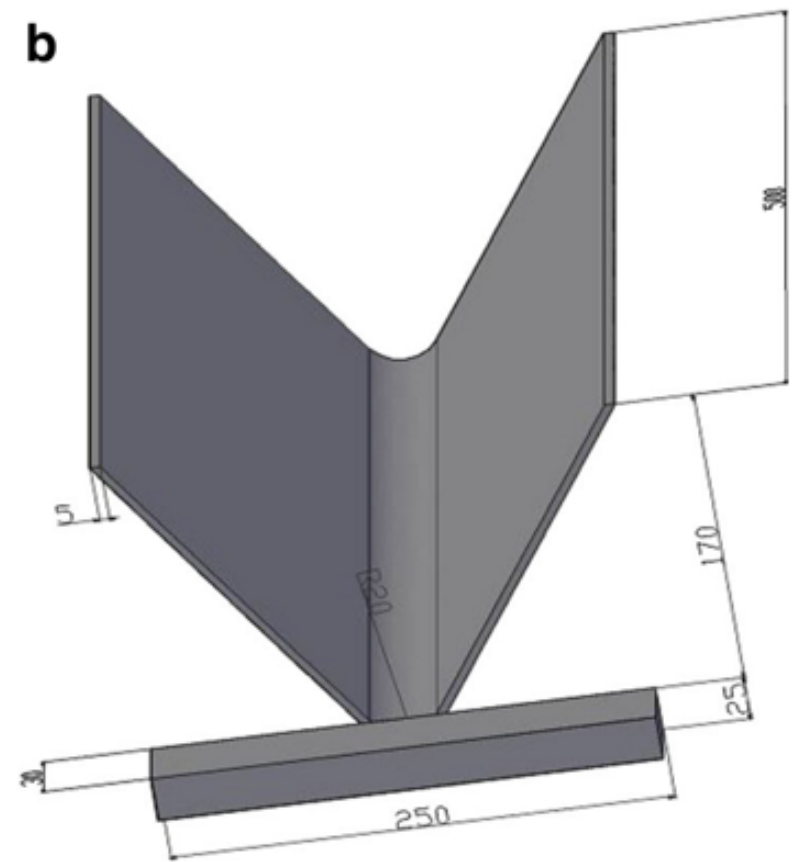

\section{Figure 1}

a Photograph of the welding robot with the GMAW torch installed. $\mathbf{b}$ Tooling used in the welding of the aluminium tube [17].

Figure 2

Macrographs of the nine experiments performed

Figure 3

Micrographs of measured grain sizes 


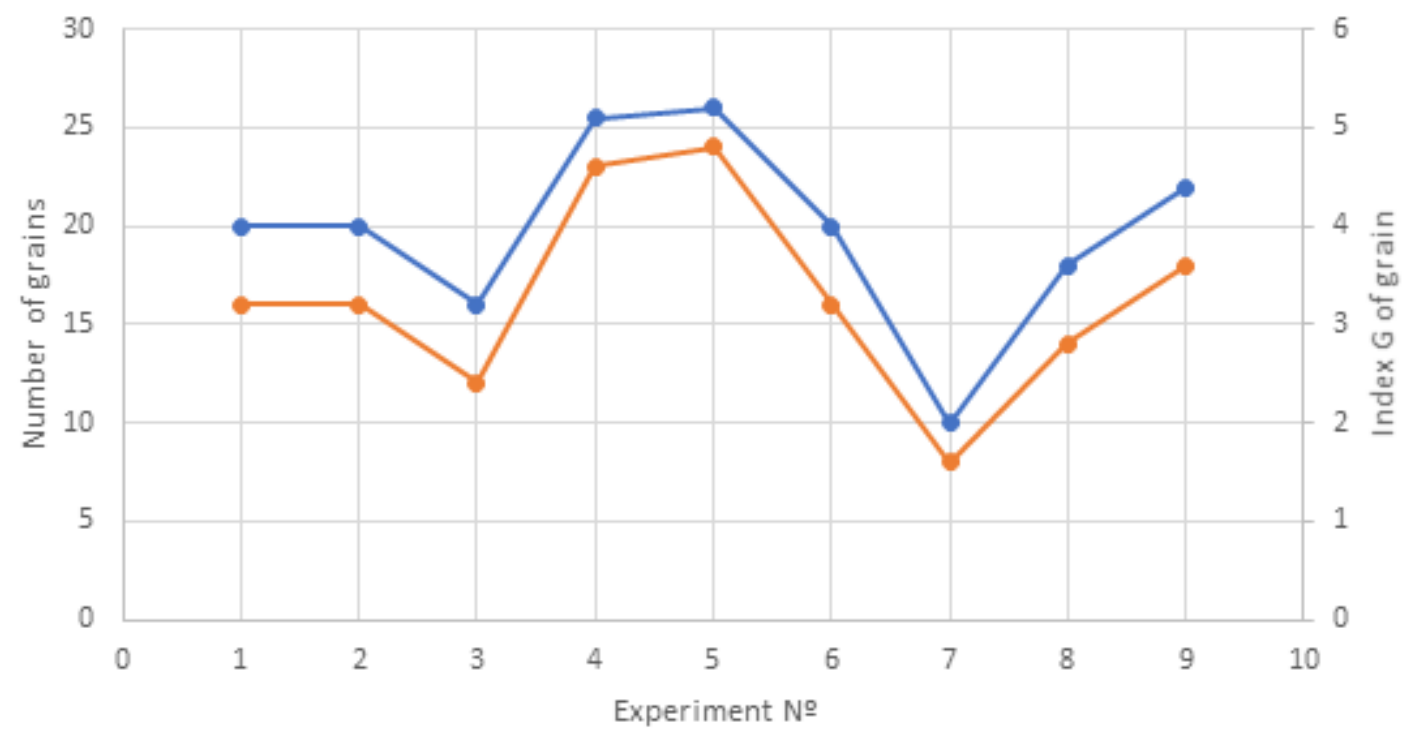

$\multimap$ Number of grains $\multimap$ Index $\mathrm{G}$ of grain

Figure 4

Relationship between G-index and grain size

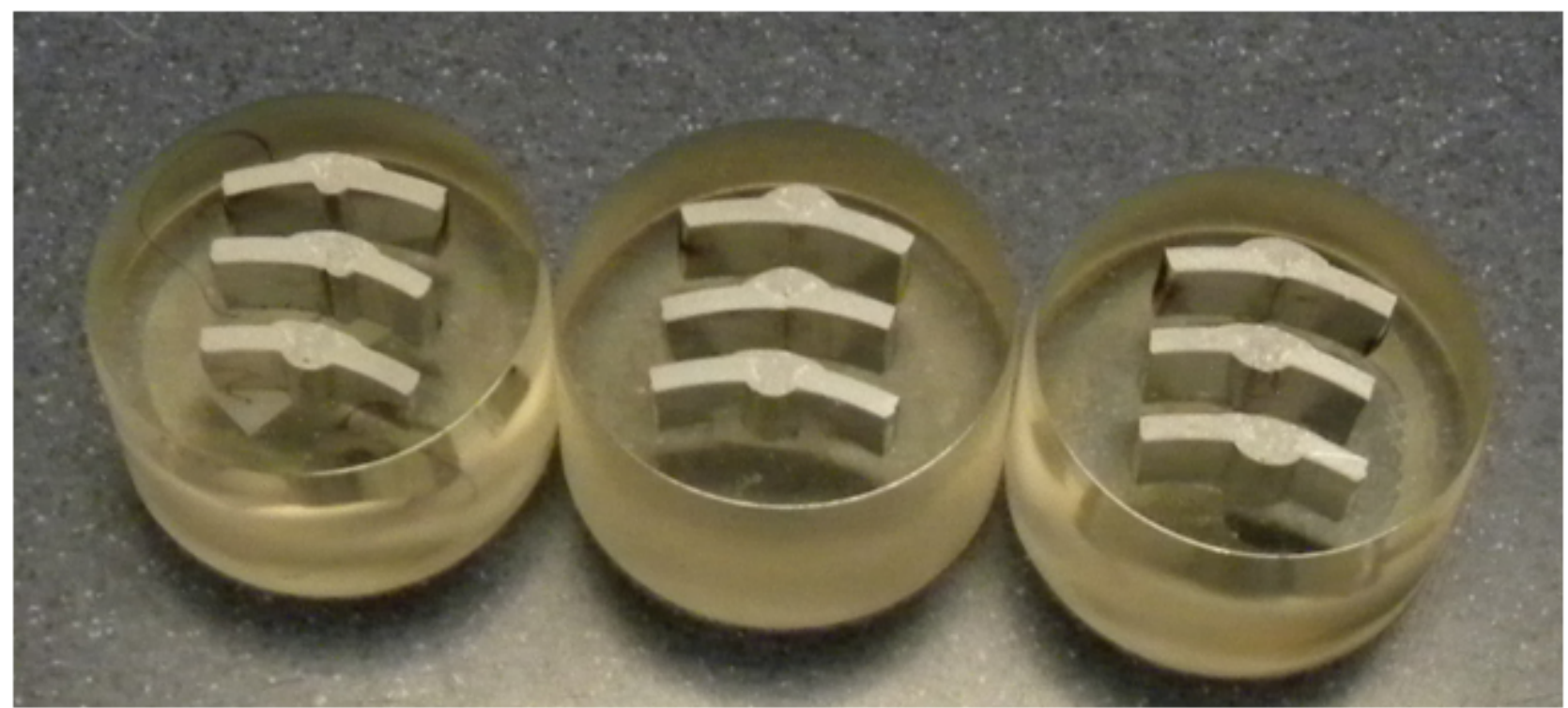

Figure 5

Macrograph of the nine experiments performed.

Figure 6 
Micrographs made on the HAZ

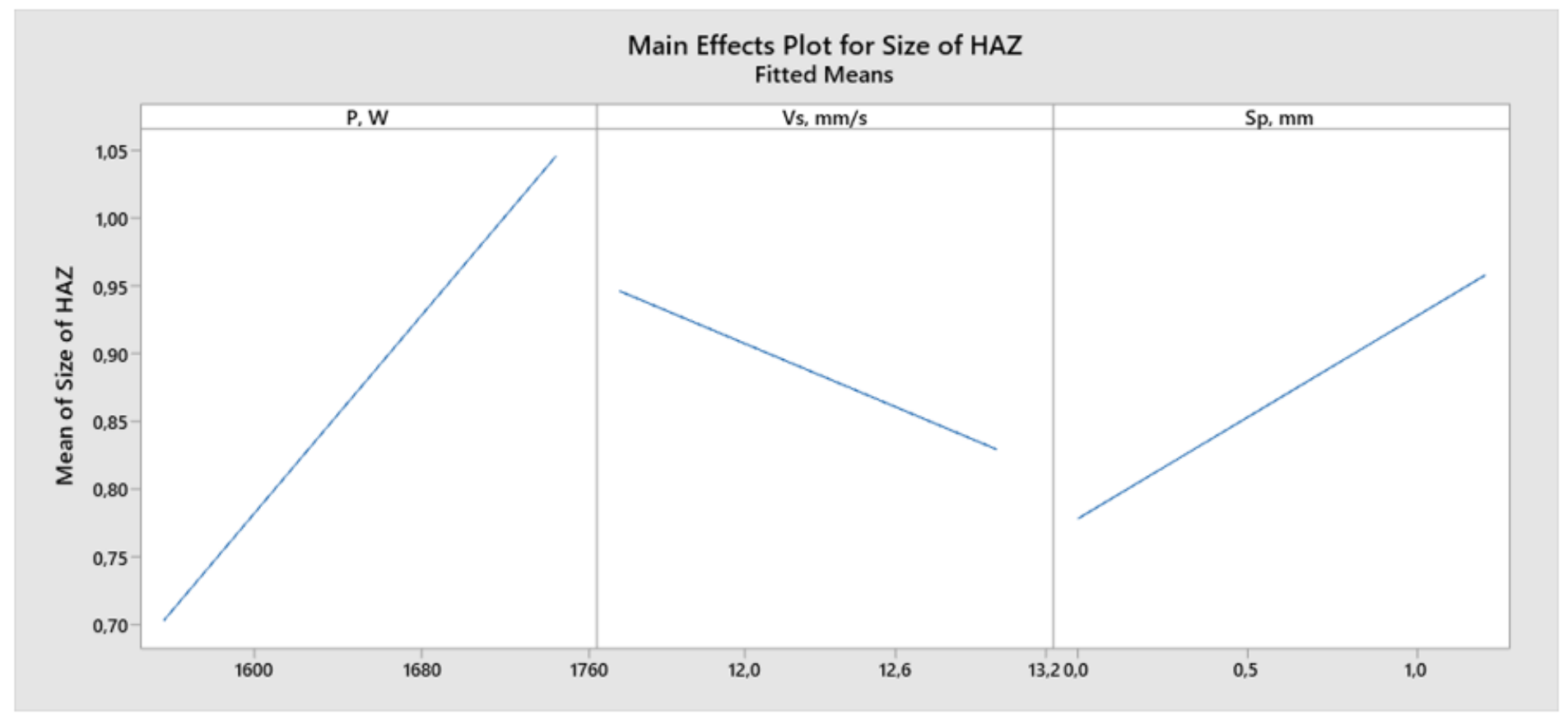

\section{Figure 7}

Representation of each of the variables with respect to the size of the HAZ

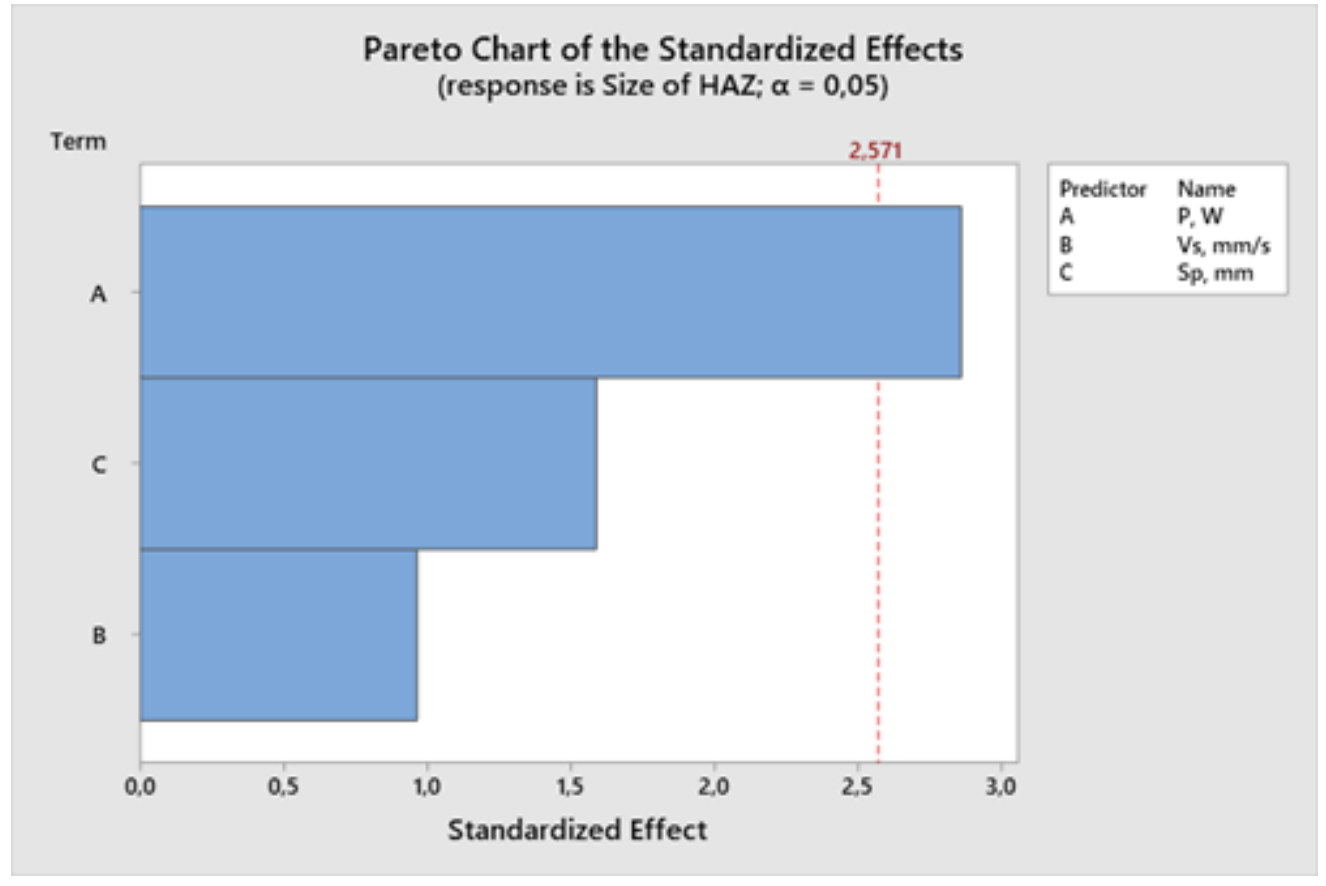

Figure 8

Pareto chart that determines the influence of variables on the size of the HAZ 

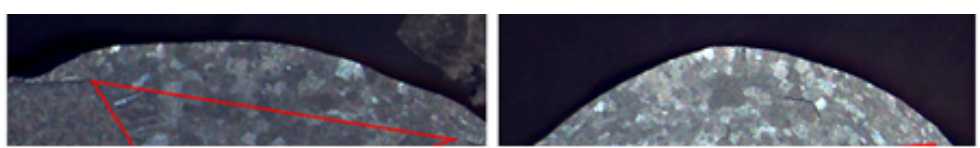

Figure 9

Dilution measured in each of the experiments. 


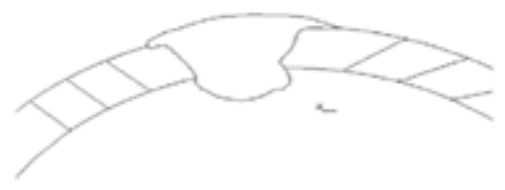

\section{Experiment 1}

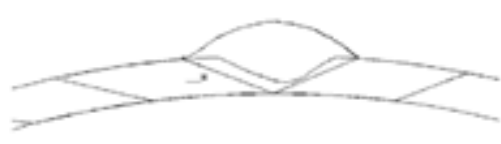

Experiment 3

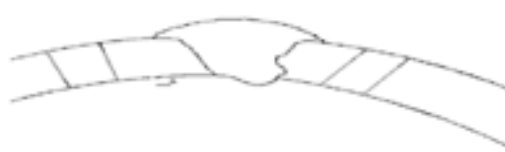

Experiment 5

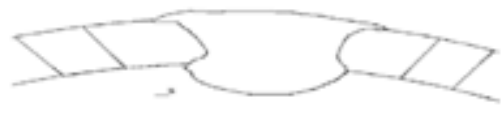

Experiment 7

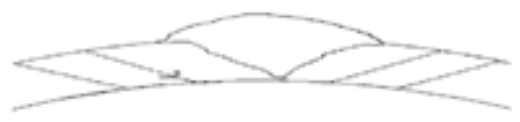

Experiment 9

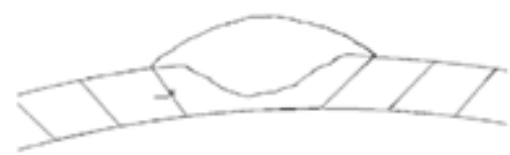

\section{Experiment 2}

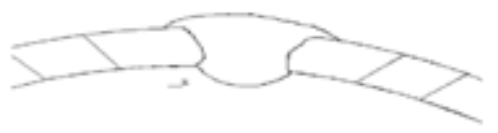

Experiment 4

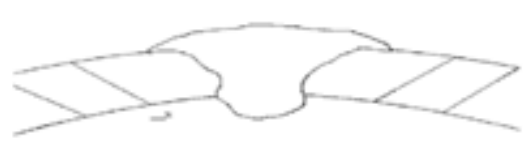

Experiment 6

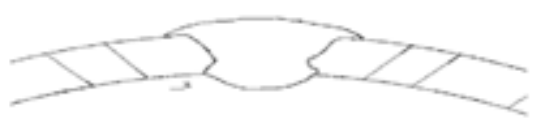

Experiment 8

\section{Figure 10}

Detailed representation of the weld bead and base metal for each of the experiments.

\begin{tabular}{|l|l|l|l|}
\hline & \multicolumn{2}{|c|}{$\begin{array}{c}\text { Main Effects Plot for Dilution } \\
\text { Fitted Means }\end{array}$} \\
\hline
\end{tabular}

\section{Figure 11}


Representation of each of the variables regarding the degree of dilution

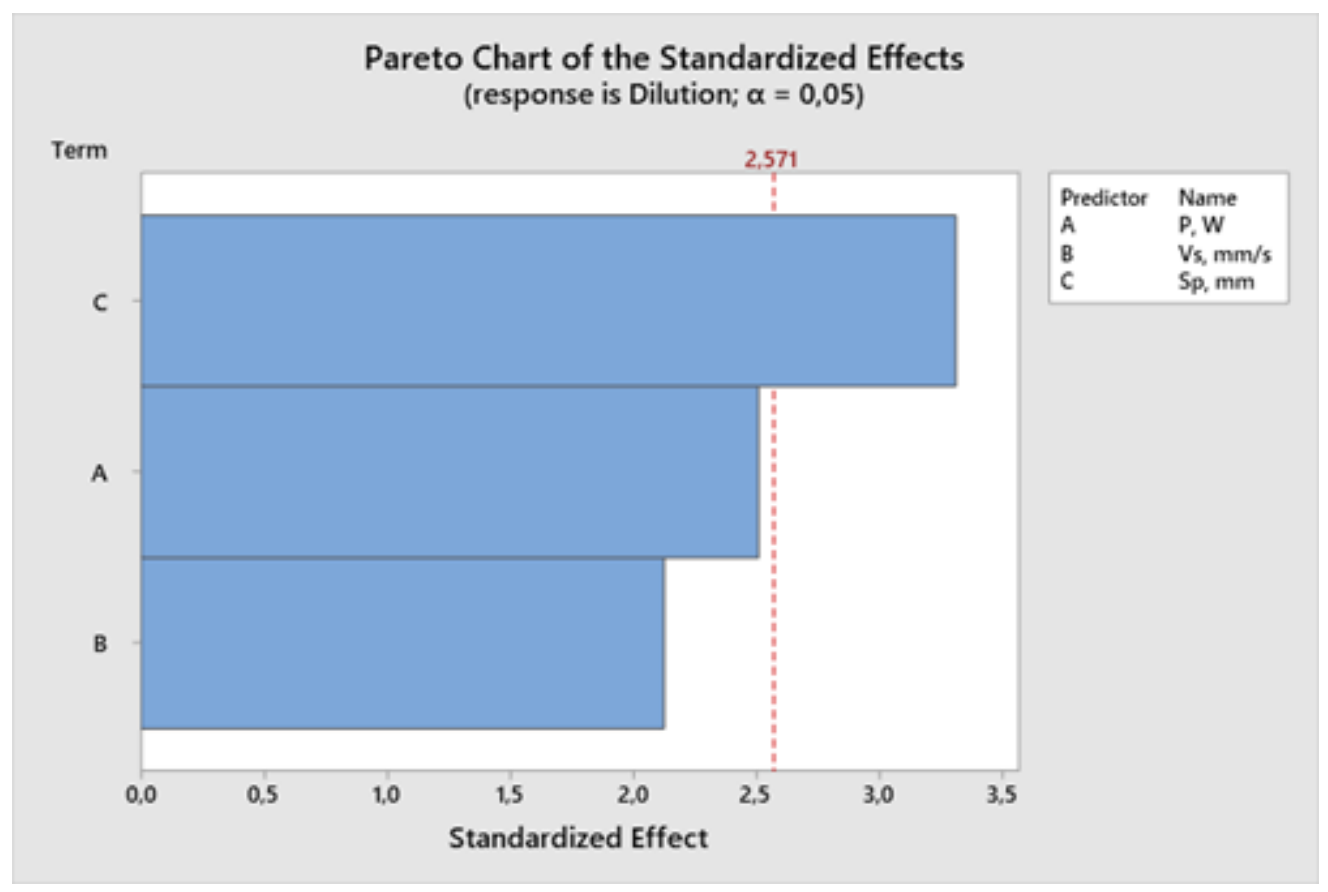

Figure 12

Pareto diagram that determines the influence of the variables on the dilution of the base metal in the weld bead..

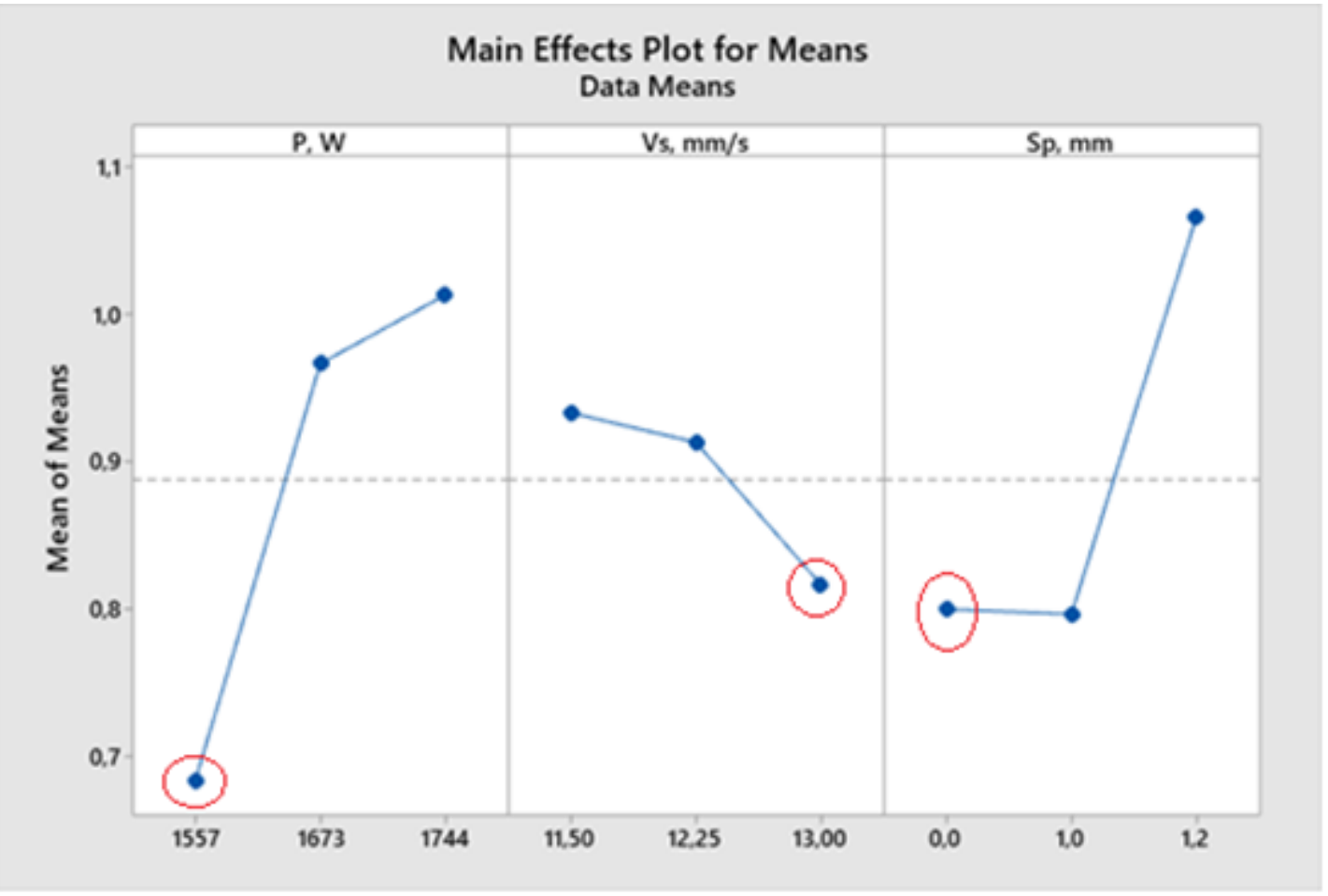

Figure 13 
Graph of the main effects of the mean values for a minimum HAZ

That is: $\mathrm{P}=1557 \mathrm{~W} ; \mathrm{Vs}=13 \mathrm{~m} / \mathrm{s} ; \mathrm{Sp}=0 \mathrm{~mm}$ obtaining a minimum value in the $\mathrm{HAZ}$ of $0.53 \mathrm{~mm}$.

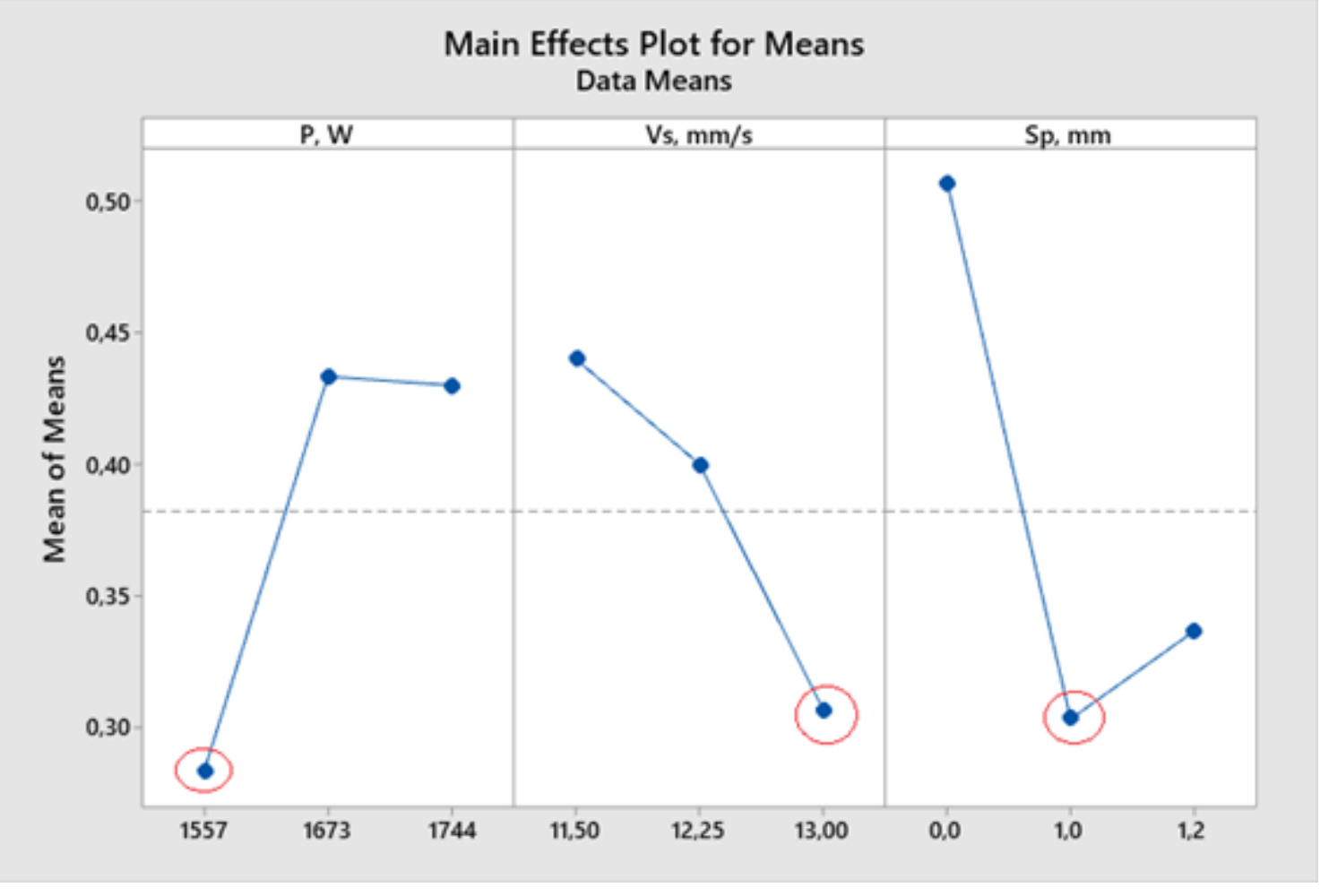

\section{Figure 14}

Graph of the main effects of the mean values for a minimum dilution

That is: $\mathrm{P}=1557 \mathrm{~W} ; \mathrm{Vs}=13 \mathrm{~mm} / \mathrm{s} ; \mathrm{Sp}=1 \mathrm{~mm}$ obtaining a minimum value of $18 \%$ dilution. 


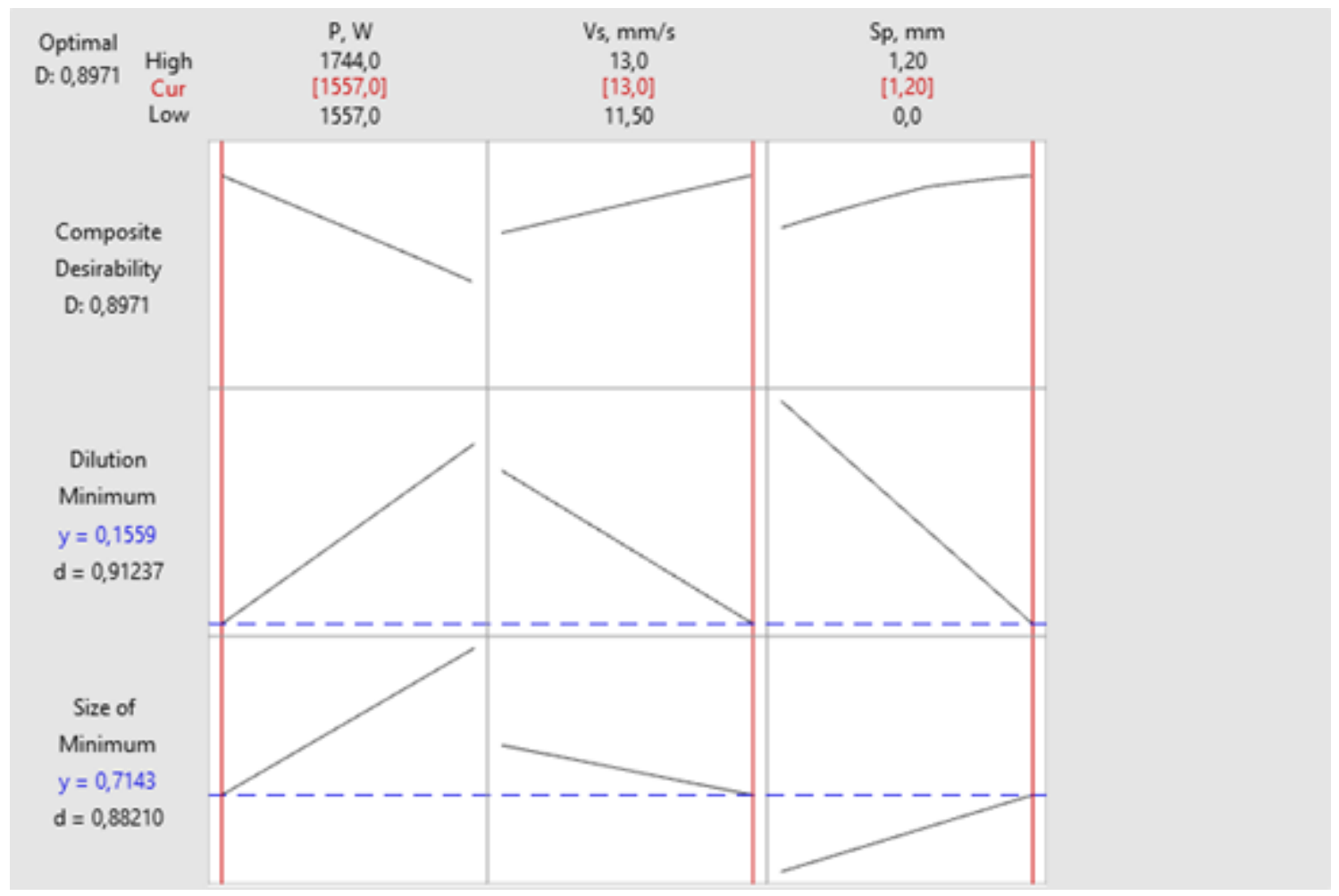

Figure 15

Optimised combination of process parameters 